Provided for non-commercial research and education use. Not for reproduction, distribution or commercial use.

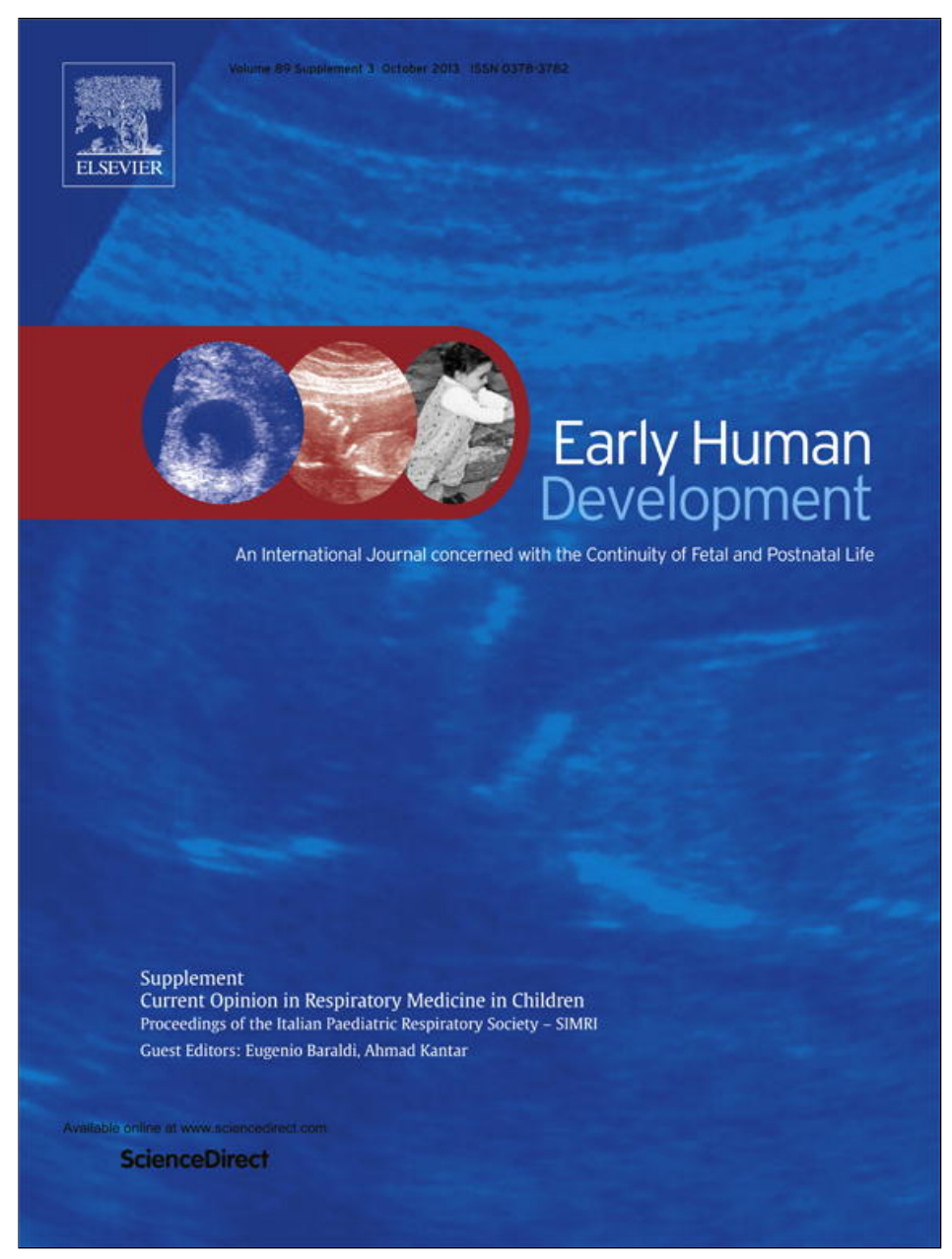

This article appeared in a journal published by Elsevier. The attached copy is furnished to the author for internal non-commercial research and education use, including for instruction at the authors institution and sharing with colleagues.

Other uses, including reproduction and distribution, or selling or licensing copies, or posting to personal, institutional or third party websites are prohibited.

In most cases authors are permitted to post their version of the article (e.g. in Word or Tex form) to their personal website or institutional repository. Authors requiring further information regarding Elsevier's archiving and manuscript policies are encouraged to visit:

http://www.elsevier.com/authorsrights 


\title{
Environmental risk factors and lung diseases in children: From guidelines to health effects ${ }^{\text {沗 }}$
}

\author{
Stefania La Grutta ${ }^{\mathrm{a}, *}$, Luciana Indinnimeo ${ }^{\mathrm{b}}$, Annalisa di Coste ${ }^{\mathrm{b}}$, Giuliana Ferrante ${ }^{\mathrm{a}, \mathrm{c}}$, Massimo Landi ${ }^{\mathrm{f}}$, \\ Umberto Pelosi ${ }^{\mathrm{d}}$, Franca Rusconi ${ }^{\mathrm{e}}$ \\ a Institute of Biomedicine and Molecular Immunology, IBIM, National Research Council, CNR, Palermo, Italy \\ b Department of Pediatrics and NPI - University of Roma "Sapienza", Italy \\ c Department for Health Promotion and Mother and Child, School of Pediatrics, Università di Palermo, Italy \\ d Children and Mother Care Department, Pediatrics Unit, S. Barbara Hospital, Iglesias, Italy \\ e Unit of Epidemiology, Meyer Children's University Hospital, Florence, Italy \\ ${ }^{\mathrm{f}}$ National System of Pediatric Primary Care asl TO 1, Turin, Italy
}

\begin{abstract}
A B S T R A C T
During the last decades research all over the world has highlighted the deleterious effects of outdoor and indoor pollution on respiratory health of adults and children. The World Health Organization (WHO) "Air quality guidelines for Europe" played a fundamental role in providing information and guidance to authorities involved in the air pollution field and they are considered the key source on which the European Commission's directive on air quality is based. Children appear to be most vulnerable to the harmful effects of outdoor pollutants, which can cause both acute exacerbations, as well as chronic respiratory symptoms and diseases. Possible mechanisms include the induction of oxidative stress, and/or allergic sensitization, as well as increased susceptibility to infections. Cigarette smoke is one of the environmental pollutant influencing morbidity and death rate in childhood as responsible for adverse health effects in both prenatal and postnatal. There is growing epidemiological evidence that indoor allergen exposure may contribute to the development of allergic respiratory symptoms. In Italy the housing and social situation, with regard to the aspects related to exposure to secondhand smoke or the presence of fungal spores, moisture linked to household vapor and poor ventilation of the rooms are problems still not completely resolved. From a medical point of view the field of pediatrics has certainly made great strides in promoting the health of children and pediatricians to have a central role for pursuing this objective.
\end{abstract}

(c) 2013 Elsevier Ireland Ltd. All rights reserved.

\section{Introduction}

Since the '80s public opinion has paid increasing attention to the question related to the effects of environmental pollution on human health. During the last decades research all over the world has highlighted the deleterious effects of outdoor and indoor pollution on respiratory health of adults and children and it is well known that millions of people live in areas where it is unsafe to breathe. Nevertheless, air pollution still represents a significant threat to health. Worldwide, the total figure for indoor air related deaths is 1.6 million per year [1]. The most recent European Union (EU) key directive on ambient air quality is Directive 2008/50/EC, where the need to reduce air pollution to levels that minimize effects on health is stressed. During the imminent "Year of the Air" the EU will revise its main air pollution control policies [2].

The World Health Organization (WHO) Regional Office for Europe, taking into account the body of evidence relating to air pollution and its

\footnotetext{
Th This article is published on behalf of the Italian Paediatric Respiratory Society (SIMRI) as part of a themed issue series on paediatric respiratory diseases.

* Corresponding author.

E-mail address: stefania.lagrutta@ibim.cnr.it (S. La Grutta).
}

health consequences, published the first edition of "Air quality guidelines for Europe" in 1987 and completed the last "global update" in 2006. These guidelines played a fundamental role in providing information and guidance to authorities involved in the air pollution field and in Europe they are considered the key source on which the European Commission's directive on air quality is based [3]. The WHO guidelines are intended as recommendations for health professionals, specialists and authorities involved in the air pollution field [3]. Air quality standards are set by each country to protect the public health of their citizens and may vary, according to the economic, political and social factors [4]. However, countries may transform the recommended guidelines into legal standards, taking into account several factors, such as the exposure level of the population, the specific mixture of air pollutants and the peculiar socioeconomic and cultural conditions [3]. Since there is epidemiological evidence that adverse health effects can remain even if the guideline value is achieved, some countries might decide to adopt lower standards than those recommended [4]. Guideline values should represent concentrations of pollutants in air with no hazards on human health. However, it would request a detailed knowledge of the dose-response relationships in relation to all sources of exposure. Such comprehensive data are generally not available, 
mainly for indoor environments. For this reason it might be accepted that a certain risk can be tolerated, taking into account that the risks to individuals within a population might not be equally distributed because of the presence of groups at considerably increased susceptibility (elderly, children, and people with chronic disease). Moreover, guidelines should consider the problem of combined exposure that often occurs both outdoors and indoors. In fact it is well known that combinations of pollutants, especially in the indoor environment, can lead to additive or synergistic effects. Therefore it would be important controlling sources of exposure, rather than focusing only on the concentration of individual pollutants [3]. Finally, it would be desirable also to consider the different pathways of exposure. Individuals might be exposed briefly or lifelong to pollutants; exposure might be occasional or occupational; individual response to exposure to pollutants may vary depending on several factors (genetics, age, sex, chronic disease and lifestyle) that can influence the different susceptibility to pollutants [3]. In conclusion, considering the detrimental effects of environmental pollution on health, urgent action is needed to reduce concentrations of dangerous compounds, especially fine particles and ozone. Many studies demonstrated that pollution reduction is associated with longer life expectancy, reduced loss of productivity and illness burdens. Therefore, policies that ensure better air quality to citizens are strongly desirable all over the world.

\section{Study designs and health effects of outdoor air pollution}

Children appear to be most vulnerable to the harmful effects of outdoor pollutants, which can cause both acute exacerbations, as well as chronic respiratory symptoms and diseases. Possible mechanisms mediating both incidence and severity effects include the induction of oxidative stress, and/or allergic sensitization, as well as increased susceptibility to infections. Some of these mechanisms may be occurring in utero, including epigenetic changes that may increase risk for the development of asthma. In addition, recent studies have reported that traffic-related air pollution may increase the risk of intrauterine growth restriction, low birth weight, and preterm birth. Given the ubiquity of air pollution exposure and the importance of the first months of life on the development of chronic lung diseases in childhood and adulthood, the availability of prospective pregnancy and birth cohort studies, designed to study the impacts of early exposures prospectively and at multiple time points, could represent a great advance also in order to infer causality.

In the following few lines we will concentrate on two topics: shortterm effects of outdoor pollution mainly from traffic sources on respiratory symptoms in children which already have asthma, and long-term effects, which are the subjects of recent systematic reviews. In fact, if smoke from domestic coal fires, and heavy industry have vanished from our skies (though these problems are still present in developing countries), motor vehicle transport has increased enormously.

Weinmayr and colleague [5], on the basis of 36 panel studies on asthmatic children, recently quantified estimates of the association of particulate matter with aerodynamic diameters $\leq 10 \mu \mathrm{g}$ (PM10) and nitrogen dioxide $\left(\mathrm{NO}_{2}\right)$, important ambient air pollutants regulated by national legislations, with respiratory symptoms and peak expiratory flow (PEF). They found evidence of effects of PM10 on the occurrence of asthma symptoms [odds ratio (OR) $=1.03 ; 95 \%$ confidence interval (CI), 1.01-1.05], and to a lesser extent on cough $(\mathrm{OR}=1.01 ; 95 \% \mathrm{CI}$ $0.99-1.03$ ) and on PEF (decrease of $-0.08 \mathrm{~L} / \mathrm{min}$; $95 \% \mathrm{Cl},-0.21$ to 0.05). Results for NO2 are more difficult to interpret, as this had significant associations with asthma symptoms in the overall analysis $(\mathrm{OR}=1.03 ; 95 \% \mathrm{CI}, 1.00-1.06)$, but not in sensitivity analysis restricted to the $0-1$ lags, which is day-time between air pollutant measurement and health endpoint. The authors pointed out that the two pollutants are only part of a more complex air pollution mixture, and that the results are not to be strictly understood as the effect of PM10 and $\mathrm{NO}_{2}$, which may be indicators of different unmeasured compounds.

Braback and colleague [6] found an evidence from recent prospective 13 cohort studies conducted in Europe, United States and Japan that long-term air pollution assessed in different ways (measurements outside home or at the community levels, distance to a large road or traffic flow, dispersions modeling, and regression models) increased respiratory symptoms in healthy children. The outcome varied with the age of the child. In infancy exposure to traffic exhaust was related to slightly increased OR for cough, asthmatic bronchitis, and upper respiratory infections, while in children an association was found with doctor diagnosis of asthma and/or reported wheeze. Such inconsistencies between countries might be related to discrepancies in the interpretation of the term "wheeze", in diagnostic labeling of symptoms and, possibly, in variability in the susceptibility to air pollution influenced by polymorphism in genes involved in airways inflammation and oxidative stress. Nevertheless, also in some previous studies the effect of air pollution was greater for infections and bronchitis than for asthma-like symptoms. The effect of air pollution on allergic sensitization in the cohort studied and analyzed was inconsistent.

Several previous prospective cohort studies also documented significant effects of outdoor air pollution on lung function development, e.g. the Californian Children's Health Study [7,8]. These results have been confirmed in prospective studies in highly polluted areas of the world [8].

Finally, in order to overcome the problem of differences in study designs on the evaluation of impact of long-term exposure to air pollution, the Pollution and the Young project [9] assembled data for $>45,000$ children from comparable cross-sectional studies in 12 countries. Positive associations were found between the average PM10 concentration and the prevalence of phlegm (OR per $10 \mathrm{mg} \cdot \mathrm{m}^{3} 1.15$, $95 \%$ CI 1.02-1.30), hay fever (OR 1.20, 95\% CI 0.99-1.46), morning cough (OR 1.15, 95\% CI 1.02-1.29) and nocturnal cough (OR 1.13, $95 \%$ CI 0.98-1.29). There were no associations with diagnosed asthma or asthma symptoms, and the association with lung function varied across the studies.

In conclusion, although the inconsistency of some results is sometimes inherent to study designs, it is important to recognize and that children still need to be protected with strict air quality standards, in order to improve their respiratory health.

\section{Health effects of environmental tobacco smoke}

Cigarette smoke is one of the environmental pollutant influencing morbidity and death rate in childhood as responsible for adverse health effects in both prenatal and postnatal. During the in utero nicotine exposure the increase in placental vascular resistances due to the toxic effects by crossing placental barrier leads to a chronic hypoxia in the fetus causing the risk grow for preterm infants, low weight infants (LBW), infants too young for gestational age (SGA) [10]. An increased risk of alterations affecting the cardiovascular apparatus, the metabolism, the nervous system and the respiratory system in infants exposed to cigarette smoke during pregnancy have been demonstrated [11]. Several negative effects on structural and functional alterations of the fetal lung of nicotine exposure were demonstrated, such as alteration of the alveolar phase, damage of the epithelial cells of type I, inhibition of fibroblasts proliferation, reduction of the small airways caliber, increase of the muscular tone and negative effects on lung compliance [12]. Therefore, a reduced lung growth, responsible for a defect in respiratory function, that persists in the postnatal period has been confirmed in nicotine exposed infants during pregnancy. The relation between smoke exposure and reduction of respiratory function was widely investigated. A study on more than 800 infants found that a reduction of some parameters related to the lung function ( $\tau_{\text {PTEF }} / \tau_{\mathrm{E}}$ e Crs) is detected at birth, particularly in males. A meta-analysis conducted out of 21 studies showed in 18 studies a reduction of the $\mathrm{FEV}_{1}$ in school age and, even if a wide heterogeneity, showed a reduction of FEV1 in school age in 18 studies, leading the authors to conclude that the exposure during pregnancy is the biggest responsible of functional alteration persisting later [13]. Further work showed that prenatal exposure 
leads to a reduction in $\mathrm{FEV}_{1}$ and $\mathrm{FEF}_{25-75}$ in children aged 6-12 years old related to the number of cigarettes smoked to which they were exposed. Other studies highlight the association between prenatal exposure and the bronchial hyperreactivity, documenting its early beginning, since the early months of life, related to a greater reduction of the $\mathrm{FEV}_{1}$. These findings demonstrate that exposure during pregnancy is responsible for permanent modifications of the respiratory track that can persist into later adulthood and may provide in the chronic obstructive pulmonary disease (BPCO). The exposure in postnatal period leads to a higher frequency of SIDS, otitis media, rasping breath, cough, infections of the upper and lower airways, tuberculosis, bronchiolitis, persistent wheezing and asthma. Regarding asthma, more frequent accesses to the emergency room, increased consumption of drugs and cases of intubation it has been shown. Many studies clarify the association between exposure to smoking and wheeze-asthma. One of the most recent meta-analysis on the association between smoking and asthma conducted on 79 studies shows that there is an increase of $\sim 20 \%$ of the risk of wheeze-asthma in children exposed to tobacco smoke [14]. Several genetic studies have been performed on the interaction smoke and genes to try to explain the differential susceptibility of children against respiratory health. These studies confirm that exposure to tobacco smoke in pregnancy increases the risk of asthma and wheezing in children with specific genetic polymorphisms aged 2 years. Gilliland et al. observed that children deficient in isoforms MI and TI GSTMI allele (glutathione S transferase) exposed in utero to smoke have a higher prevalence of early-onset asthma that persists in later life [15]. Maternal smoking in the prenatal period is closely associated with the risk of wheeze-asthma in children aged 2 years, while maternal smoking and not the paternal one in postnatal age increases the risk of asthma in children aged 5-18 years.

In conclusion, in utero exposure increases the risk of incidence of asthma, while exposure at school age is associated with an increased risk of severity and exacerbations and may be considered a risk factor for its persistence in later life.

\section{Health effects of other indoor pollutants}

Infants and children spend more than $80 \%$ of their time at home, school and public spaces [16]. The total individual exposure to an indoor pollutant is given by the measured concentration of the pollutant where air is breathed. Indoor pollutant concentration depends on external environmental pollutants filtered inside buildings, pollutants generated inside buildings (domestic work) and pollutants generated by personal activities. Cooking, heating, particle suspension, building materials, air conditioning and consumer products, such as chemicals used for house cleaning, are principal sources of indoor pollutants. Combustion products (eg. tobacco smoke and wood burning), $\mathrm{CO}, \mathrm{CO}_{2}$, volatile organic compounds (VOC e.g. aldehydes, alcohols, alkanes and ketones), microbial agents (fungi and bacterial endotoxins), organic products (pet derived and mite allergens, dampness, mold derived components), radon and artificial vitreous fibers are most important indoor pollutants. Short-term health effects by indoor pollution are acute respiratory symptoms (wheezing, coughing, mucus production, infections), changes in lung and cardiovascular function. Long-term health effects include increased incidence and prevalence of chronic respiratory (asthma, COPD) and cardiovascular diseases, permanent changes in respiratory function, problems in fetal growth (low birth weight, intrauterine growth retardation), lung cancer and hospitalization and mortality for cardiovascular and respiratory diseases.

However the health effects attributed to indoor pollutants concern mainly on airways and lungs. Asthma has become the most common chronic disease in childhood in industrialized countries, responsible for social problems, low school performance and absenteeism. Allergens, nitrogen dioxide $\left(\mathrm{NO}_{2}\right)$, carbon dioxide $\left(\mathrm{CO}_{2}\right)$ and fine particles are the principal investigated indoor pollutants associated with respiratory effects.
There is growing epidemiological evidence that indoor allergen exposure may contribute to the development of allergic respiratory symptoms. The early exposure may trigger early onset: association of current wheeze with mold/dampness exposure seemed stronger in children than in adolescents, and more evident with early than with current exposure [17]. Mite-related allergens are considered one of the major biogenetic indoor factors. This is supported by strong evidence for a causal relationship with the onset of allergic diseases such as asthma and perennial rhinitis. Homes rather than public places can represent the environment where people can incur easily in mite allergy. Other asthma symptom inducing widespread allergen is Fel $\mathrm{d}$ 1 , major cat allergen. A dose-response relationship between exposure (threshold: 1-2 $\mu$ g allergen/g of dust) and sensitization to indoor allergens, as well as between exposure (threshold: 8-10 $\mu$ g allergen/g of dust) and symptoms development has been established. Schools, workplaces and homes are at risk for cat allergen exposure. More recently, VOC, emitted by various sources have been independently associated with respiratory symptoms. The exposure to numerous chemicals, painting, redecoration activities, flooring and renovations, are potential emissions of VOC. Formaldehyde is the most concerning pollutant, with high chronic and carcinogenic risk, followed by naphthalene, benzene, and toluene [18]. Phthalates are constituents of numerous chemicals used as plasticizers and show positive associations with childhood asthma. Ozone $\left(\mathrm{O}_{3}\right), \mathrm{NO}_{2}$ and particulate matter (PM) are potent oxidants, either through direct effects on lipids and proteins or indirectly through the activation of intracellular oxidant pathways. In preschool inner-city children, high indoor $\mathrm{NO}_{2}$ concentrations are associated with statistically significant increase of respiratory symptoms [19]. Exposure to pollutants such as airborne PM and $\mathrm{O}_{3}$ has been associated with higher morbidity, hospital admissions and mortality for respiratory and cardiovascular diseases. Common household activities, especially smoking and sweeping, and ambient PM contribute to indoor PM concentrations. In asthma patients, PM exposure is significantly associated with severe respiratory symptoms and decreased lung function. Exposure to indoor traffic-related pollutants $\left(\mathrm{PM}, \mathrm{NO}_{2}\right.$, diesel soot, organic components) is associated with high risk of obstructive bronchitis in children. Indoor particle size has different respiratory impact in early childhood. The strongest health impact was observed when the mass concentration of particles is $<1 \mu \mathrm{m}$ and the number concentration of particles is $>0.5 \mu \mathrm{m} / \mathrm{cm}^{3}[20]$. Children who grow up in crowded urban neighborhoods have higher rates of asthma morbidity: it has been shown that indoor PM concentration in inner city homes is more than three times greater than suburban home environment. Early life exposure to adverse lifestyle factors and disadvantaged urban environment seems to increase allergic diseases and asthma risk. Further studies are needed to evaluate the most efficacious and feasible methods for improving indoor air quality and respiratory health of children.

\section{Role of pediatrician in prevention}

In Italy the pediatrics of family represented by a network of pediatricians ensures a widespread coverage of the whole territory. This cover has a particularly important role in all the qualities associated to preventive and social sphere, like support of immunization, prevention of obesity, chronic diseases and environmental control. For this, the direct contact with the household and the home visit allows the pediatrician to enhance the ongoing relationship with the young patients and his/her relatives in order to capture important information about the lifestyle of single family unit. At the stage of acquiring information, it can and should follow a phase of information and education to parents on how to reduce or prevent the most common environmental hazards. In Italy the housing and social situation, with regard to the aspects related to exposure to secondhand smoke or the presence of fungal spores, moisture linked to household vapor and poor ventilation of the rooms are problems still not completely resolved [21] The provision of educational leaflets dedicated is certainly a good way to tackle the problem, 
but in most cases, these books are left in the waiting rooms and the correct penetrance message remains in fact it is controlled, families need to be involved, made partakers and somehow made complicit. Educational aspects are to be interpreted as a therapy for a chronic disease and, as is well known, the therapeutic adherence in chronic diseases is often lacking. It could therefore overcome this problem by dedicating the spaces of time in meetings with small groups of parents in order to properly present the problem and emphasize the most important aspects that are often overlooked or underestimated. Educational aspects should be directed to the entire pediatric population of the physician, and not necessarily to selected families, so that messages are disseminated more widely. It is the task of every physician who is well aware of its reality, to do well on those cases more delicate and more involved in the issue. The opportunity could also be used for educational aspects related to respiratory diseases in general (correct use of drugs, devices, etc.). Aspects of passive smoking are certainly the most important and generally those on which there is a greater quantity of material.

Since the pediatrician interacts with children and their parents for a long time, taking care of all the health issues, is the leading actor for the educational activiries in order to achieve the better health status and avoid/remove all the modifiable risk factors [22]. In addition, this aspect could be particularly important in a context like the present when the working structure of the family has changed, the management of the children became more complicated, and economic conditions have worsened [23]. However, so that we can implement interventions pediatric ad hoc is necessary that there be adequate training for professionals to really affect the behavior of parents and adolescents [24]. This training could take place during the years of specialization or in specialized training events. In conclusion, from a medical point of view the field of pediatrics has certainly made great strides in promoting the health of children, however, the WHO defined health as a state of complete physical, mental and social, and not merely the absence of disease [25]. Preventive and educational aspects have a central role in this objective and the pediatrician is the central role for pursuing it.

\section{Conflict of interest}

The authors have no conflict of interest to report.

\section{References}

[1] Annesi-Maesano I, Heinrich J, Ayres JG, Forastiere F. Why an ERJ series on air pollution? Eur Respir J 2012;40:12-3.

[2] Brunekreef B, Annesi-Maesano I, Ayres JG, Forastiere F, Forsberg B, Kunzli N, et al. Ten principles for clean air. Eur Respir J 2012;39:525-8.

[3] WHO. Guidelines for indoor air quality: selected pollutants; 2010.
[4] WHO. Air quality guidelines for particulate matter, ozone, nitrogen dioxide and sulfur dioxide. Global 2005 [update].

[5] Weinmayr G, Romeo L, De Sario M, Weiland SK, Forastiere F. Short-term effects of PM10 and NO2 on respiratory health among children with asthma or asthma-like symptoms: a systematic review and meta-analysis. Environ Health Perspect 2010:118:449-57.

[6] Bråbäck L, Forsberg B. Does traffic exhaust contribute to the development of asthma and allergic sensitization in children: findings from recent cohort studies. Environ Health 2009;8:17.

[7] Gauderman WJ, Avol E, Gilliland F, Vora H, Thomas D, Berhane K, et al. The effect of air pollution on lung development from 10 to 18 years of age. $\mathrm{N}$ Engl J Med 2004;351:1057-67.

[8] Gotschi T, Heinrich J, Sunjer J, Künzli N. Long-term effects of ambient air pollution on lung function: a review. Epidemiology 2008;19:690-701.

[9] Hoek G, Pattenden S, Willers S, Antova T, Fabianova E, Braun-Fahrländer C, et al. PM10, and children's respiratory symptoms and lung function in the PATY study Eur Respir J 2012;40:538-47.

[10] Lambers DS, Clark KE. The maternal and fetal physiologic effects of nicotine. Semin Perinatol 1996;20:115-26.

[11] Campos M, Bravo E, Eugenin J. Respiratory dysfunctions induced by prenatal nicotine exposure. Clin Exp Pharmacol Physiol 2009;36:1205-17.

[12] Sekhon HS, Proskocil BJ, Clark JA, Spindel ER. Prenatal nicotine exposure increases connective tissue expression in fetal monkey pulmonary vessels. Eur Respir 2004;23:906-15.

[13] Cook DG, Strachan DP, Carey IM. Health effects of passive smoking. 9: parental smoking and spirometric indices in children. Thorax 1998;53:884-93.

[14] Burke H, Leonardi-Bee J, Hashim A, Pine-Abata H, Chen Y, Cook DG, et al. Prenatal and passive smoke exposure and incidence of asthma and wheeze: systematic review and meta-analysis. Pediatrics 2012;129:735-44.

[15] Gilliland FD, Li YF, Dubeau L, Berhane K, Avol E, McConnell R, et al. Effects of glutathione S-transferase M1, maternal smoking during pregnancy, and environmental tobacco smoke on asthma and wheezing in children. Am J Respir Crit Care Med 2002;166: 457-63.

[16] Heinrich J. Influence of indoor factors in dwellings on the development of childhood asthma. Int J Hyg Environ Health 2011;214:1-25.

[17] Simoni M, Lombardi E, Berti G, Rusconi F, La Grutta S, Piffer S, et al Mould/dampness exposure at home is associated with respiratory disorders in Italian children and adolescents: the SIDRIA-2 study. Occup Environ Med 2005;62:616-22.

[18] Sofuoglu SC, Aslan G, Inal F, Sofuoglu A. An assessment of indoor air concentrations and health risks of volatile organic compounds in three primary schools. Int J Hyg Environ Health 2011;214:36-46.

[19] Hansel NN, Breysse PN, McCormack MC, Matsui EC, Curtin-Brosnan J, Williams DL, et al. A longitudinal study of indoor nitrogen dioxide levels and respiratory symptoms in inner-city children with asthma. Environ Health Perspect 2008;116:1428-32.

[20] Franck U, Herbarth O, Röder S, Schlink U, Borte M, Diez U, et al. Respiratory effects of indoor particles in young children are size dependent. Sci Total Environ 2011;409: 1621-31.

[21] Brent RL, Weitzman M. The pediatrician's role and responsibility in educating parents about environmental risks. Pediatrics 2004;113:1167.

[22] Stein RJ, Haddock CK, O'Byrne KK, Hymowitz N, Schwab J. The pediatrician's role in reducing tobacco exposure in children. Pediatrics 2000;106:e66.

[23] Satcher D, Kaczorowski J. Topa D. The expanding role of the pediatrician in improving child health in the 21st century. Pediatrics 2005;115:1124.

[24] Hymowitz N, Schwab J, Eckholdt H. Pediatric residency training on tobacco. Presented at the Fifth International Congress of Behavioral Medicine. Copenhagen, Denmark: Hellerup, International Conference Services; 1998.

[25] WHO. Definition of health. Available at www.who.int/about/definition/en. [Accessed July 30, 2004]. 